\title{
Didactics of Physical Education: The Case of Motivational Students Profiles in Pole Vaulting Performance
}

\author{
Chawki Derbali', Ali Elloumi2 ${ }^{2}$, Fathi Matoussi ${ }^{3}$ \\ ${ }^{1}$ High Institute of Physical Education and Sport of Gafsa, University of Gafsa, Gafsa, Tunisia \\ ${ }^{2}$ Faculty of Human Sciences of Sfax, University of Sfax, Sfax, Tunisia \\ ${ }^{3}$ High Institute of Education and Continuing Training of Tunis, Virtual University of Tunis, Tunis, Tunisia \\ Email: derbali chawki@yahoo.fr
}

Received 12 June 2015; accepted 12 July 2015; published 15 July 2015

Copyright (C) 2015 by authors and Scientific Research Publishing Inc.

This work is licensed under the Creative Commons Attribution International License (CC BY).

http://creativecommons.org/licenses/by/4.0/

(c) (i) Open Access

\begin{abstract}
This work attempts to determine the students' motivation in physical education area through analyzed clusters. As a particular topic in Tunisia we highlight the relationship between motivational profiles and the students' performance in pole vaulting. For this, three grades' students (37 girls, 32 boys) from randomly selected sport-studies classes provided data questionnaire (SMS-II adapted; Pellier et al., 2013) on motivation levels and their pole vaulting performance achievement. This was evaluated using a pre- and post-assessment design of 7 -weeks pole vault teaching. obtained results concern the reliability and the validity of the sport motivation scales questionnaire. Cluster analyses revealed two motivational profiles: non-self-determined and self-determined levels of motivation. The self-determined motivation profile was correlated to the highest pole vault performance. The theoretical and practical implications for the measurement of students' motivation in pole vault practice are discussed. The effects of motivational profiles on students' pole vault achievement are perceived.
\end{abstract}

\section{Keywords}

Motivation Profile, Self-Determination, Pole Vault, Performance, Physical Education Student

\section{Introduction}

Motivation is one of the important controlling factors in physical education. Previous works stated that practice of sport in physical education (PE) may affect students' motivation considering its potential to provide expe-

How to cite this paper: Derbali, C., Elloumi, A., \& Matoussi, F. (2015). Didactics of Physical Education: The Case of Motivational Students Profiles in Pole Vaulting Performance. Creative Education, 6, 1349-1359. 
riences for the student population (Molanorouzi, 2015; Hagger et al., 2003). Thus, the increase of athletic performance and the need to produce well-educated citizens encourage to study students' motivation profiles with the integration of new performance sports in physical education setting.

Our study is based on self-determination theory (SDT). This is an organismic dialectical approach that starts on the assumption that people have active organisms, with developed tendencies towards growing, mastering ambient challenges, and integrating new experiences into a coherent sense of self. The SDT is considered as comprising five mini-theories (Deci \& Ryan, 1985) developed to explain a set of motivationally based phenomena that emerged from laboratory and field research dealing with various facet of motivation or personality functioning. Cognitive Evaluation Theory (CET) concerns the satisfactions of behaving with intrinsic motivation, and how some factors (rewards, interpersonal controls, ego-involvements) impact intrinsic motivation and interest in education, sport and other domain. Organismic Integration Theory (OIT) concerns the topic of extrinsic motivation in its various forms, with their properties, determinants, and consequences. It particularly highlights supports for autonomy and relatedness as critical to internalization. Causality Orientations Theory (COT) describes individual differences in people's tendencies to orient toward environments and regulate behavior in various ways. It describes and assesses three types of causality orientations: the autonomy orientation in which persons act out of interest in what is occurring. Basic Psychological Needs Theory (BPNT) elaborates the concept of evolved psychological needs and their relations to psychological health and well-being. The Goal Contents Theory (GCT) grows out of the distinctions between intrinsic and extrinsic goals and their impact on motivation and wellness. Goals are seen as basic need satisfactions, differentially affording and then associated with well-being. Extrinsic goals (financial success, appearance, and popularity/fame) have been specifically contrasted with intrinsic ones (community, close relationships, personal growth); the formers being associated with lower wellness and greater ill-being. According to basic psychological needs theory (BPNT), a subtheory within SDT, when these psychological needs are fulfilled, effective functioning and well-being occur. For example, Gagné, Ryan, and Bargmann (2003) found that fluctuations in youth female gymnasts' daily need for satisfaction positively predicted fluctuations in indices of psychological well-being (i.e., subjective vitality, positive effect, and self-esteem) over a four-week period. Similarly, satisfying individuals' psychological needs has been positively linked to performance and quality of adjustment in the workplace (Baard, Deci, \& Ryan, 2004), psychological well-being in exercise contexts (Wilson, Longley, Muon, Rodgers, \& Murray, 2006), and lower burnout in athletes (Lonsdale, Hodge, \& Rose, 2008).

Based on the principles of Deci and Ryan (1985) concerning Self-Determination Theory (SDT), Vallerand (1997) has developed the Hierarchical Model of Intrinsic and Extrinsic Motivation (HMIEM). This conceptual model for studying the sequence of motivational processes impacts outcomes such as persistence behavior and well-being in various applied domains including sport. The original version of the HMIEM includes five postulates all leading to a broad overview of human motivation and adaptive processes, operating at three distinct but interactive levels of analyses. The global level concerns the typical or enduring motivational orientation towards engaging in life's activities (Vallerand, 1997). The situational level refers to the moment-to-moment variations in the immediate environment (Vallerand, 1997). Between the global and situation levels resides the contextual level that refers to the motivational processes that operate within particular spheres of life such as education, work, and sport (Vallerand, 1997). The sequence of processes related to adaptive functioning and integration within each level of the HMIEM remain consistent despite variation in the level of generality. In the original development of the HMIEM, Vallerand (1997) presented a four-stage sequence of motivational processes that operate at each level of generality comprising the model: Social Factors-Psychological Need FulfillmentMotivation-Consequences (Mageau \& Vallerand, 2003).

The concept of basic psychological needs is the main object in SDT and the HMIEM. According to Deci and Ryan (2002), the needs for competence, autonomy and relatedness denote innate, rather than acquired, human tendencies that promote adaptation and enhance well-being when fulfilled authentically. Within the framework of the HMIEM, Vallerand (1997) stated that these basic psychological needs represent the lynch pin connecting perceptions of the social environment with individual motivation. On the other hand, it is advanced that, within the HMIEM, social factors such as the degree of experienced success/failure will influence motivation via the satisfaction of competence, autonomy, and relatedness needs (Vallerand, 2007). This distinction has been analyzed in sport (Pelletier et al., 2001), exercise (Wilson \& Rodgers, 2004), and physical education (Rouse, Ntoumanis, \& Duda, 2013).

Regarding the conceptualization of SDT, Vallerand and Fortier (1998) have suggested that motivation is mul- 
tidimensional in nature and that SDT constructs should not be treated separately. Other works have shown that the motivational regulations are not contradictory (Fairchild, Horst, Finney, \& Barron, 2005; Lepper \& Henderlong, 2000). Similarly, Vallerand (1997). It is noted that individuals can exhibit multiple types of motivation for a single behaviour and that these can merge to create different motivational profiles. The individual profile in physical activity (PA) motivation embraces a person-centered research approach, as recently recommended by Friederichs et al. (2015). In the educational context, it is stated that students can exhibit diverse motivation profiles connected to academic accomplishment (Boiché et al., 2008). In sports area, some works highlighted both self-determined and non-self-determined profiles that have linked to outcomes such as objective performance (Gillet et al., 2013). Cluster analysis studies also correlated self-determined profiles to better physical self-worth (Biddle \& Wang, 2003). Thus, it was stated that two to four profiles would emerge, showing levels of PA in general. However, there is no detailed study about the students' motivational profile focused on the pole vault activity integrated in the physical education field.

A virtual inquiry concerns the relatively predictive intensity of the different types of motivational profiles that could result from cluster investigation. Therefore, how motivation profiles can be interesting in predicting important outcomes in physical education and sports (PES), such as engagement, performance, or score?

The aim of this search is both theoretical and empirical. From a theoretical perspective, it attempts to clarify how the different forms of motivation proposed by SDT should be combined. From an empirical point of view it proposes to identify the motivational profiles of academic sport-studies classes and the corresponding proportions of students who display such profiles.

Hence the objective is twofold: 1) to measure the motivation which would appear among students from Tunisia with a classification of their motivation profiles into examined clusters; 2) to verify the relation between various motivational profiles observed and the students’ performance in pole vaulting activity.

\section{Methods}

\subsection{Participants and Procedure}

Sixty nine students (37 girls, 32 boys) from a Tunisian school of sport-studies classes volunteered to participate in the study. They were from secondary school in first-grade $(N=23)$, second-grade $(N=25)$, and third-grade $(N=21)$ classes. Their ages ranged between 15.8 and 17.6 years $(M=16.53$ years, $S D=1.14)$. In Tunisia, physical education is an obligatory subject for all secondary school students. Physical education courses include different sports and physical activities during seven-week cycles (i.e., 14 lessons each during 1 hour). Participants practice pole vaulting for parallel 7-week cycles (i.e., 7 lessons of 2 hours each). The study was conducted during integrated pole vaulting cycle in adapted and scheduled physical education lessons of a sport-studies class. Students' motivations for the activity were assessed at the first lesson, during the cycle lessons and at the end of the cycle. Therefore, participants completed a 21-item instrument designed to assess motivation. All students were videotaped individually in order to evaluate their performance in pole vaulting.

\subsection{Measurement}

Motivation: Motivation in pole vaulting was assessed, at the beginning, during and at the end of the cycle. A preliminary adaptation of motivation scales in sport (Brière, Vallerand, Blais, \& Pelletier, 1995) and in education (Vallerand et al., 1989) was of a great interest. This adaptation was developed in English to assess physical education motivation (Standage et al., 2006) as in gymnastics cycle (the Sport Motivation Scale SMS-II, Luc G. Pelletier et al., 2013). This was performed to fit both the sportive and educational aspects of pole vaulting as a topic of physical education. These tools assessed the multifaceted motivational regulations proposed by SDT. Based on the subscale, the items were specially personalized from one tool to another. For example, the intrinsic motivation scales (IMS) were largely differentiated from the extrinsic motivation scale (EMS). The adaptation specified changes in the wording of some items to target the pole vaulting context and/or a translation in English. Seven motivational constructs relative to physical education were assessed in a 21-item scale. The participants had to complete the following sentence: "I practice pole vaulting because/for..." with items reflecting IM to word stimulation (e.g., "for the excitement I feel when I am really involved in the pole vaulting activity”), IM to ward knowledge (e.g., Because I really enjoy learning new techniques) IM to accomplishment (e.g., "Because I find it enjoyable to discover new performance strategies.”), identified regulation (e.g., "because what I learn in 
this activity will be useful later"), introjected regulation (e.g., "because I would feel bad if I could not succeed in this activity"), external regulation (e.g., "because that's what I'm supposed to do"), and amotivation (e.g., “I don't know why I go in pole vaulting, if I could, I would get exempted"). The English version of the full scale is accessible in Table 1. Responses were completed on a 7-point scale ranging from 1 (strongly disagree) to 7 (strongly agree).

Performance in pole vaulting: Students' performance in pole vaulting was based on a test consisting of six pole vault learning phases (e.g., run up, plant, takeoff, swing, rock back, bar clearance). The students were videotaped separately during the pole vaulting cycle of learning period. Three athletics expert rated the videotaped performance of each student on a 1 (low level) to 7 (high level) response scales. Each expert observed the videotapes independently and made a single global score for the student's performance after viewing all six learning

Table 1. Items of the Motivation Scale with Corresponding Factor Loadings: "I practice pole vaulting...”.

\begin{tabular}{ccc}
\hline & Exploratory Confirmatory \\
Factor & Factor Analysis \\
Analysis & Acale & Ans \\
\hline
\end{tabular}

\section{IM To ward Stimulation}

Because this activity is exciting.

$\begin{array}{ll}0.87 & 0.76 \\ 0.91 & 0.83 \\ 0.73 & 0.81\end{array}$

For the physically powerful enjoyment that I feel while I am doing this sport.

0.73

\section{IM To ward Knowledge}

For the pleaser of discovering new training techniques.

$\begin{array}{ll}0.74 & 0.65 \\ 0.67 & 0.82 \\ 0.85 & 0.77\end{array}$

Because it is very interesting to learn new performance strategies.

0.85

0.77

\section{IM To Accomplishment}

For the pleaser that I feel while executing certain difficult movements.

$\begin{array}{ll}0.86 & 0.93 \\ 0.65 & 0.71 \\ 0.76 & 0.62\end{array}$

For the pleasure I feel while improving some of my weak points.

0.76

0.62

\section{Identified Regulation}

Because doing sport's activity reflects the motor ability of who I am.

$0.88 \quad 0.92$

Because what I am taught in this activity will be helpful for other things.

0.81

Because it fits well with my personal development.

\section{Introjected Regulation}

Because it is possible to succeed in this activity if I take the enough time doing it.

$\begin{array}{ll}0.79 & 0.76 \\ 0.68 & 0.65 \\ 0.72 & 0.63\end{array}$

Because I would feel bad if I could not do well in this sport.

0.72

\section{External Regulation}

To show others how good I am at this activity.

$\begin{array}{ll}0.92 & 0.84 \\ 0.59 & 0.61 \\ 0.62 & 0.57\end{array}$

For the esteem of being a pole-vaulter.

Because that's what I'm supposed to do.

0.62

\section{Amotivation}

I don't know why I go in pole vaulting, if I could, I would get exempted.

I don't know anymore; I have the impression that I am incapable of succeeding in this sport.

0.81

It is not clear to me anymore; I don't really think my place is in sport.

Note: This table presents an English translation of the French items used in the studies. EFA = Exploratory Factor Analysis; CFA = Confirmatory Factor Analysis. 
phases. The mean of the three experts' scores was calculated and considered as an index of students' pole vault performance. This method has been used in previous works relative to physical education classes (e.g., Chanal, Marsh, Sarrazin, \& Bois, 2005). A test of Inter-rater reliability evaluated the consistency of how the rating system is carried out. For example, if one expert accords a "1" to a student performance in pole vaulting, while another expert gives a "7", evidently the inter-rater reliability would be inconsistent. Inter rater reliability is dependent upon the ability of two or three individuals to be more consistent. Training in pole vaulting can enhance inter rater reliability. While the "true" inter rater reliability coefficient is based on the whole participants in the activity performance, its estimated value (normally used in practice) is obtained from a population study. Should be considered as valid, any estimated inter-rater reliability coefficient that differs from its "true" value by no more than $20 \%$ of the "true" value. The $20 \%$ is arbitrary used, and depends on the size of the population study (Gwet, 2008a).

Grade: After accomplishment of the pole vaulting cycle, all teachers provided the grades obtained by the students in pole vaulting competition; grades are scores being comprised between 0 and 20, the score of 10 is ordinarily considered a mean measure.

\subsection{Data Analysis}

The confirmatory factor analysis was processed to test the scale's factor structure of the questionnaire assessing students' motivation. Then, the correlations between motivational scores were observed. An exploratory cluster analysis was carried out to identify the motivational profiles. A determination of the cluster composition according to gender was established. Lastly, an analysis of variance (ANOVA) was performed to test whether motivational profiles can predict student performance in pole vaulting.

\section{Results}

\subsection{Exploratory Factor Analysis}

The number of items was adjusted at 21. Hence, the Factor analysis showed seven factors with Eigenvalues above the recommended cutoff (Cattell, 1966) which explained over $70 \%$ of the total variance. The varimax rotation delivered from the rotated component matrix to optimize the differences between factors, was observed to examine the item loadings. As exposed in Table 1, the items loaded cleanly on the appropriate factors representing IM to knowledge, IM to stimulation, IM to achievement, identified regulation, introjected regulation, external regulation, and amotivation, and revealed the structure of 21-items, 7-factor of sport motivation scales of pole vault (SMS-PV). All of the retained items had a loading above 0.58 .

\subsection{Confirmatory Factor Analysis}

According to SPSS statistics based on AMOS model (Arbuckle, 2011), a confirmatory factor analysis was advanced. The factor loadings are shown in Table 1 . The resultant seven factor CFA model was significant ( $\mathrm{X}^{2}$ $(34)=197, p<0.01$ ). The other indices suggested that the fit of the seven-factor model to the data was satisfactory to very good: $\mathrm{RMSEA}=0.06$; RMSEA $90 \% \mathrm{CI}=0.04-0.06$; $\mathrm{CFI}=0.93$; NFI $=0.91$; $\mathrm{TLI}=0.92$. Item-factor loadings ranged from 0.61 to $\left.0.93 ; \mathrm{X}^{2}(15)=12.40, p>0.1\right)$ which means that the gender is invariant with regards to SMS-PV factor structure. Composite variables can be safely created from each factor scores.

\subsection{Reliability Analysis}

The reliability of each subscale was calculated using Cronbach's alpha $(\alpha)$. The results are summarized in Table 2. The adapted SMS-PV shows good reliability values for all subscales where Cronbach's alpha equal to or greater than 0.70 . The reliability for all the new introjected regulation items was analyzed aiming to confirm the higher reliability of different item combination or the potential compromising of a specific item to the reliability of the subscale. The reliability for the six proposed introjection items showed a higher reliability ( $\alpha$ ranged from 0.71 to 0.92$)$.

\subsection{Equations Correlational Analysis}

Composite scores were calculated for each of the subscales. The inter-subscale correlations were calculated from sport motivation scales questionnaire to inspect the fit of the simplex pattern. The correlation matrices can be 
Table 2. Means, Standard Deviations and Correlations Between the Motivation Variables.

\begin{tabular}{|c|c|c|c|c|c|c|c|c|c|c|}
\hline Variable & M & SD & A & 2 & 3 & 4 & 5 & 6 & 7 & 8 \\
\hline 1) IM To ward Stimulation & 4.08 & 1.25 & 0.92 & $0.67^{* * *}$ & $0.65^{* * *}$ & $0.47^{* * *}$ & $0.51^{* * *}$ & $0.27^{* *}$ & -0.06 & $0.33^{* * *}$ \\
\hline 2) IM To ward Knowledge & 3.96 & 1.31 & 0.87 & & $0.78^{* * *}$ & $0.45^{* * *}$ & $0.62^{* * *}$ & $0.21^{* *}$ & -0.04 & $0.38^{* * *}$ \\
\hline 3) IM To Accomplishment & 4.03 & 1.36 & 0.89 & & & $0.47^{* * *}$ & $0.49^{* * *}$ & $0.24^{* *}$ & -0.09 & $0.29^{* * *}$ \\
\hline 4) Identified Regulation & 3.57 & 1.69 & 0.71 & & & & $0.53^{* * *}$ & $0.42^{* * *}$ & 0.07 & $0.21^{* * *}$ \\
\hline 5) Introjected Regulation & 3.85 & 1.52 & 0.73 & & & & & $0.46^{* * *}$ & 0.02 & $0.18^{* *}$ \\
\hline 6) External Regulation & 3.64 & 1.61 & 0.85 & & & & & & $0.35^{* * *}$ & $0.15^{* *}$ \\
\hline 7) Amotivation & 3.09 & 1.79 & 0.77 & & & & & & & $-0.25^{* * *}$ \\
\hline 8) Performance in Pole vault & 4.11 & 1.86 & - & & & & & & & \\
\hline
\end{tabular}

Note: IM = intrinsic motivation; $\mathrm{N}(69) ;{ }^{* * *} p<0.001$ (2-tailed); ${ }^{* *} p<0.01$ (2-tailed).

viewed in Table 2. These suggest evidence of a simplex-like pattern that have acceptable consistence, over than 0.68, stronger between subscales situated closer along the SDT continuum, and weaker for the subscales falling further away on the sport motivation scales continuum. All subscales fit cleanly the simplex pattern as expected.

\subsection{Outcome in Motivation Continuum}

The matrix outlining correlations between the motivation subscales in outcomes is exposed in Table 3. It was anticipated that motivation subscales would report the strongest correlations with the equivalent subscales on the sport motivation continuum and then support a cross-scale simplex pattern. According to SDT, vitality, satisfaction with physical well-being, and task orientations should be highly associated to autonomous forms of motivation. In line, it was examined that those outcomes would have stronger correlations with the autonomous subscales of the motivation continuum, the opposite being expected for ego orientation. The results indicate stronger correlations for those close to the motivation scale continuum, and lower correlations as we move along the motivation continuum. Ego orientation was more strongly associated with the non-self-determined forms of motivation while task orientation was more strongly associated with the self-determined forms of motivation. The correlation coefficient changes in trends when we move from amotivated regulation to intrinsic motivation via extrinsic regulation.

\subsection{Simplex Pattern}

Correlations among the constructs are shown in Table 2. The correlations between the variables appear to be in conformity with a simplex structured matrix, while we found some deviations from this presumed pattern. In fact, IM towards stimulation and accomplishment displayed a more important relationship with identified regulation (0.47) than with external regulation (0.27). In addition, introjected regulation showed significant correlations with IM toward stimulation (0.51), IM towards knowledge (0.62), IM towards accomplishment (0.49), identified regulation (0.53) and correlation with external regulation (0.23), and absent correlation with amotivation (0.02).

\subsection{Cluster Analysis}

Given the fact that the internal consistency of subscales proved to be satisfactory (Table 2), the average of the scores was calculated for each subscale. Performing cluster analysis from recommended procedure of Hair et al. (1998), was carried out. All the variables included in a cluster analysis have to share the same characteristics. It is considered that each of them contributes equally to the formation of the clusters and was comparable in terms of age and gender. The entire motivational constructs were assessed on a 7-point scale. Analyses illustrated no distance from the mean greater by triple than the standard deviation value. On the other hand, multicollinearity between variables may illustrate impact on the cluster analysis by loading more growth to collinear variables. Resulting that no Bravais-Pearson correlation coefficient was upper than 0.80 , that perform consideration with 
Table 3. Descriptive Statistics for Cluster 1 and 2, and Mean Differences (T-test).

\begin{tabular}{|c|c|c|c|c|c|c|}
\hline \multirow[b]{3}{*}{ Variable } & \multirow{2}{*}{\multicolumn{2}{|c|}{$\begin{array}{c}\text { Cluster } 1(\mathrm{~N}=44) \\
\text { Self-determined motivation }\end{array}$}} & \multicolumn{2}{|c|}{ Cluster $2(\mathrm{~N}=25)$} & \multirow{2}{*}{\multicolumn{2}{|c|}{ T-test }} \\
\hline & & & \multicolumn{2}{|c|}{ Non self-determined motivation } & & \\
\hline & M & SD & M & SD & $\mathrm{t}$ & $p$ \\
\hline 1) IM To ward Stimulation & 4.45 & 1.41 & 1.21 & 0.89 & 15.24 & $<0.001$ \\
\hline 2) IM To ward Knowledge & 4.32 & 1.47 & 1.33 & 0.93 & 14.47 & $<0.001$ \\
\hline 3) IM To Accomplishment & 4.28 & 1.62 & 1.37 & 0.86 & 14.23 & $<0.001$ \\
\hline 4) Identified Regulation & 3.86 & 1.33 & 2.11 & 0.68 & 11.53 & $<0.001$ \\
\hline 5) Introjected Regulation & 3.65 & 1.56 & 2.36 & 0.77 & 7.20 & $<0.001$ \\
\hline 6) External Regulation & 3.52 & 1.21 & 3.79 & 1.68 & 0.36 & $=0.443$ \\
\hline 7) Amotivation & 1.07 & 0.91 & 5.03 & 1.88 & 17.84 & $<0.001$ \\
\hline 8) initial Performance in Pole vault & 3.43 & 1.43 & 2.92 & 1.57 & 3.28 & $<0.001$ \\
\hline 9) final Performance in Pole vault & 4.68 & 1.66 & 3.54 & 1.71 & 6.49 & $<0.001$ \\
\hline 10) Grade & 14.27 & 3.15 & 10.13 & 4.11 & 18.65 & $<0.001$ \\
\hline
\end{tabular}

Note: $\mathrm{IM}=$ intrinsic motivation

this cluster correlation (Hair et al., 1998). A hierarchical cluster analysis was prearranged by means of Ward's method with a squared Euclidean distance measure. The Identified number of clusters was performed using The agglomeration schedule and dendrogram. A high increase of the agglomeration schedule (37\%) suggested the two cluster solution to be suitable. Figure 1 shows the profiles of those two clusters. The first was labeled "self-determined motivation" profile and represented $64 \%$ of the sample $(\mathrm{N}=44)$. Participants in this cluster revealed high levels of self-determined forms of motivation (i.e., IM, identified regulation), moderate level of introjected regulation external regulation (with a scores ranged from 3.52 to 3.86) and low level of amotivation. The second cluster was labeled "non-self-determined motivation" profile and represented 36\% of the sample (N = 25). Participants in this cluster presents low levels of self-determined forms of motivation (i.e., IM; identified regulation), a low level of introjected regulation, and relatively high levels of external regulation and amotivation. The results of t-tests examining profile group differences between all variables without extrinsic regulation (Table 3). The clusters' size, as well as the means and standard deviations of their centered, are shown in Table 3. A multivariate analysis of variance (MANOVA) showed a significant effect of cluster membership on the seven motivational constructs (see Table 3; Wilks's lambda $=0.13$, Rao $R(13,404)=58.29, p<0.001$ ). Follow-up ANOVAs revealed a significant effect of cluster membership on each motivational construct. Newman-Keuls post hoc analyses $(p<0.01)$ indicated that the two level groups were significantly distinct from each other on all motivational scales, except for external regulation between the self-determined motivation and the non self-determined motivation profiles.

\subsection{Motivational Profile and Pole Vault Achievement}

An ANOVA was carried out to test whether motivational profile was linked to different levels of achievement among students, represented by their final performance in the pole vault activity. The analysis was significant, $F$ $(4,125)=7.12, p<0.01, \eta^{2}=0.08$. Newman Keuls post hoc analyses $(p<0.01)$ revealed that the two clusters were distinct on final pole vault performance in pole vaulting (Table 3), with students in the self-determined cluster showing the highest average performance $(M=4.68)$, distinguished to the non-self-determined cluster $(\mathrm{M}=3.54)$.

\section{Discussion}

Our results support the reliability and validity of sport motivation scales of pole vault activity. The cluster analysis approach identified different types of students' motivation profiles to state motivational clusters of pole vaulting. They showed two self-determined motivational clusters from two students' classes of sport-studies, 


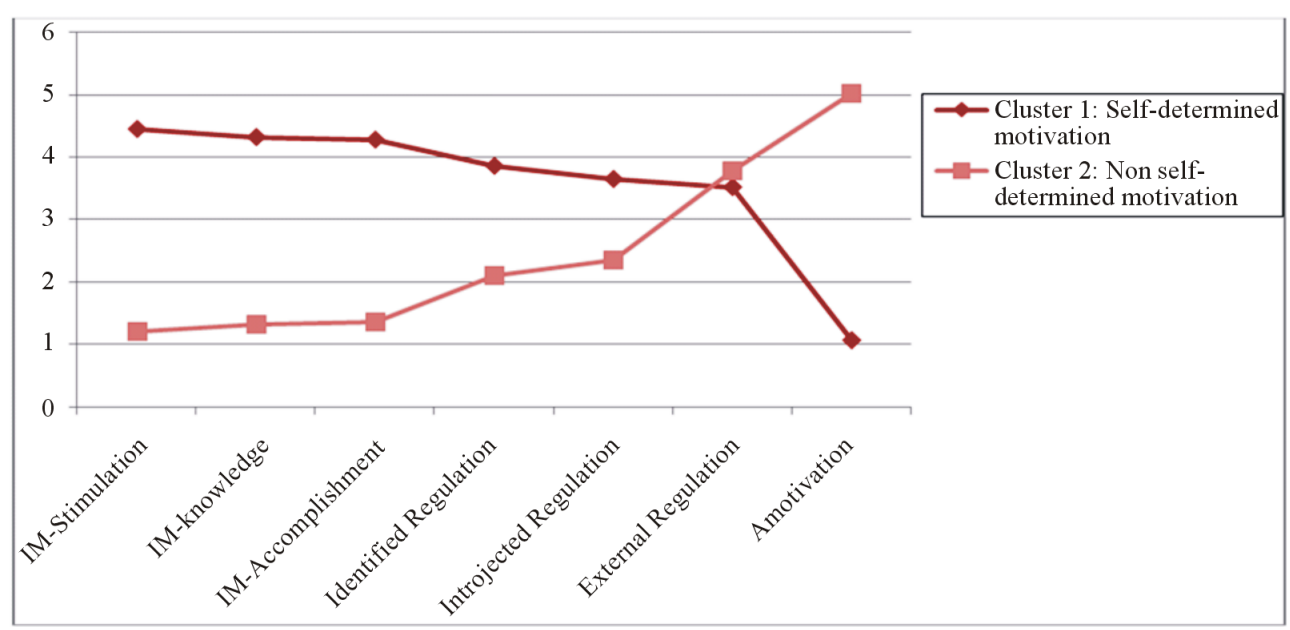

Figure 1. Motivation profiles.

revealing different patterns in the controlling processes concerning students' motivation towards pole vaulting performance. Were also analyzed the relationships between the resultant self-determined and non-self-determined motivational profiles with pole vault performance in PE. Two motivational profiles including students with moderate scores for all motivational scales were identified. It therefore appears possible to combine both self-determined and non-self-determined forms of motivation when they persist moderately developed in the extrinsic regulation. Although a prospective design was adopted, the correlative data does not allow affirming that the different motivational profiles observed were the only cause for different levels of performance at the end of the pole vaulting cycle. Otherwise, the opportunity that differentiated in initial performance could be understandable from the motivational profiles observed. Consequently, it seems important to control the initial performance to more accurately evaluate the potential impact of motivation on final performance. Furthermore, conditions other than performance should also be used as representative of achievement.

The SDT draws that introjected and extrinsic regulations are located towards the extrinsic endpoint of the self-determination continuum (Deci \& Ryan, 1991). Consequently, we could consider that students in the "selfdetermined motivation profile" should express low levels of introjected regulation and extrinsic motivation, and low down motivation profile (Vallerand \& Fortier, 1998). Vallerand et al. (1997) have suggested that introjected regulation can lead to adaptive consequences in school education context. Furthermore, in the sport case, identified regulation has been previously considered to be related to long term determination (Pelletier et al., 2013), while to the opposite limit on motivation continuum, introjection has been previously considered to be related to short term persistence (Pelletier et al., 2001) but not to long-term determination. In the context of pole vaulting in physical education, some students may decide to be active participants, not for the reason of taking pleasure in pole vaulting, but for showing how good they are at this activity and for the esteem of being a pole-vaulter. According to (Ryan \& Deci, 2007), in the preinternalization stage, external regulations could be transformed into internal ones. Sometimes, students engage in pole vaulting activity solely because that's what they are supposed to do. These results are confirmed by Pelletier et al. (2013) in physical education area. Extrinsic regulation can positively affect pole vaulting performance, a relatively new delicate practice of sport performance to integrate in the field of physical education. As the video registration was appreciable, some students may have tried to do the exercise just because this effort would be evaluated. Video recording could explain why no significant difference was observed between the moderate profile and the self-determined profile for this variable. However, this superficial effort does not seem sufficient to make enough improvement. In fact, because there was a significant difference in terms of final performance between those two groups' profiles even after controlling for initial performance in the pole vault activity. Their final pole vault performance was expected to be related to their initial potential, motivational profile, and attempts. Otherwise, for a comparable initial pole vault performance in the activity, we estimated that expending further effort and being more self-determined for the activity would result in a privileged improvement, and thus in a higher final performance. The pole vaulting grade obtained was perceived to result not only in students' final outcome, but also during learn sequences; that is, their initial pole vault performance and motivation as well as the objective effort they exerted. Physical edu- 
cation teachers, desire have motor-active learners, better than their level of ability (e.g., Biddle \& Goudas, 1997). They might also consider preliminary characteristics of their students such as motivation and performance to form prospect on their achievement, which may impact on the grade they give them at the end of the learning period (e.g., Trouilloud, Sarrazin, Martinek, \& Guillet, 2002). Whereas, upper students' performance may still more highly related to intrinsic motivation to word stimulation, acknowledgement and accomplishment. In this study, analyses showed that students who expresses a self-determined profile were those who achieved the most during the cycle of pole vault: more effort was grounded, better was the final performance, and so, obtaining better grades than did the students showing different profiles. By opposition, students who showed a non-selfdetermined profile were those who achieved less. In fact, teacher spending more time listening to their students and acknowledging their perspective, provide more sustain for the quality of students' performance and growth, and give confidence for more choice, initiative and participation in decisions (Gillet et al., 2014; Grolnick \& Ryan, 1989). By against, controlling educators use more commands, offer more solution to learners, criticize them more, and put more pressure using rewards, threats, and deadlines. There is empirical evidence showing that the degree to which teachers are autonomy supportive versus controlling is significantly linked with students' need satisfaction and motivations as mainly in physical education (e.g. Reeve, 2002; Standage et al., 2003). Gagné et al. (2003) proposed that both autonomy support and structure are needed to lead to the internalization of the activity. Although the educational climate was not taken into account in the present study, previous works suggested that a teacher showing characteristics of an autonomy supportive climate and providing structure to the students would contribute to the development of a self-determined motivational profile beneficial for achievement.

\section{Conclusion}

This work provides preliminary indicators regarding the specific forms of motivation which might be involved in students sport performance. Cluster analyses were carried out to observe motivational profile levels. These profiles support the interactional assumption concerning the relationships between motivational components (e.g., Pintrich \& Maehr, 2002). The first cluster was oriented toward the self-determined part of the continuum of motivation, with high levels of intrinsic motivation, identified regulation, moderate levels of introjected and external regulations and low level of amotivation. The second cluster was directed toward the non-self-determined components of the continuum, among learners scoring high on external regulation and amotivation, and low on other forms of motivation. These results underscore that determined motivation can predict final pole vault performance and grade of students attending sport-studies class and the importance of considering gender difference in this sport practice. For future studies, we can underline some limitations to our approach. The validity of pole vault activity integration in physical education can be questioned. In addition, the significance for the path between effort, stress, support autonomy and final performance can be a subject of future research. The duration of the cycles was also relatively short, and the beneficial effects of motivation observed in tow short cycles would probably be more important in studies carried out during a long period of time as a year or several years. Finally, it seems important to make a scientific synthesis for the evolution of physical education and questioning actors of the noosphere about worries and challenges for the integration of the pole vault activity in educational environment.

\section{References}

Arbuckle, J. L. (2011). Amos 20 User's Guide (Example 26, pp. 385-408). Chicago, IL: SPSS Inc.

Baard, P. P., Deci, E. L., \& Ryan, R. M. (2004). Intrinsic Need Satisfaction: A Motivational Basis of Performance and WellBeing in Two Work Settings. Journal of Applied Social Psychology, 34, 2045-2068. http://dx.doi.org/10.1111/j.1559-1816.2004.tb02690.x

Biddle, S. J. H., \& Wang, J. C. K. (2003). Motivation and Self-Perception Profiles and Links with Physical Activity in Adolescent Girls. Journal of Adolescence, 26, 687-701. http://dx.doi.org/10.1016/j.adolescence.2003.07.003

Biddle, S., \& Goudas, M. (1997). Effort Is Virtuous: Teacher Preferences of Pupil Effort, Ability and Grading in Physical Education. Educational Research, 39, 350-355. http://dx.doi.org/10.1080/0013188970390310

Boiché, J. C. S., Sarrazin, P. G., Grouzet, F. M. E., Pelletier, L. G., \& Chanal, J. P. (2008). Students’ Motivational Profiles and Achievement Outcomes in Physical Education: A Self-Determination Perspective. Journal of Educational Psychology, 100, 688-701. http://dx.doi.org/10.1037/0022-0663.100.3.688 
Brière, N. M., Vallerand, R. J., Blais, M. R., \& Pelletier, L. G. (1995). Development and Validation of a Measure of Intrinsic, Extrinsic and Amotivation in the Sport Context: The Echelle de Motivation dans les Sports (EMS). International Journal of Sport Psychology, 26, 465-489.

Cattell, R. B. (1966). The Data Box: Its Ordering of Total Resources in Terms of Possible Relational Systems. In R. B. Cattell (Ed.), Handbook of Multivariate Experimental Psychology (pp. 67-128). Chicago, IL: Rand-McNally.

Chanal, J. P., Marsh, H. W., Sarrazin, P. G., \& Bois, J. E. (2005). Big-Fish-Little-Pond Effects on Gymnastics Self-Concept: Social Comparison Processes in a Physical Setting. Journal of Sport and Exercise Psychology, 27, 53-70.

Deci, E. L., \& Ryan, R. M. (1985). Intrinsic Motivation and Self-Determination in Human Behavior. New York: Plenum. http://dx.doi.org/10.1007/978-1-4899-2271-7

Deci, E. L., Vallerand, R. J., Pelletier, L. G., \& Ryan, R. M. (1991). Motivation in Education: The Self-Determination Perspective. Educational Psychologist, 26, 325-346. http://dx.doi.org/10.1080/00461520.1991.9653137

Deci, E., \& Ryan, R. (2002). Handbook of Self-Determination. Rochester, NY: University of Rochester Press.

Fairchild, A. J., Horst, S. J., Finney, S. J., \& Barron, K. E. (2005). Evaluating Existing and New Validity Evidence for the Academic Motivation Scale. Contemporary Educational Psychology, 30, 331-358. http://dx.doi.org/10.1016/j.cedpsych.2004.11.001

Friederichs, S. A., Bolman, C., Oenema, A., \& Lechner, L. (2015). Profiling Physical Activity Motivation Based on SelfDetermination Theory: A Cluster Analysis Approach. BMC Psychology, 3, 1-12. http://dx.doi.org/10.1186/s40359-015-0059-2

Gagné, M., Ryan, R., \& Bargmann, K. (2003). Autonomy Support and Need Satisfaction in the Motivation and Well-Being of Gymnasts. Journal of Applied Sport Psychology, 15, 372-390. http://dx.doi.org/10.1080/714044203

Gillet, N., Lafreniere, M. A., Vallerand, R. J., Huart, I., \& Fouquereau, E. (2014). The Effects of Autonomous and Controlled Regulation of Performance-Approach Goals on Well-Being: A Process Model. British Journal of Social Psychology, 53, 154-174. http://dx.doi.org/10.1111/bjso.12018

Gillet, N., Vallerand, R. J., \& Paty, B. (2013). Situational Motivational Profiles and Performance with Elite Performers. Journal of Applied Social Psychology, 43, 1200-1210. http://dx.doi.org/10.1111/jasp.12083

Grolnick, W. S., \& Ryan, R. M. (1989). Parent Styles Associated with Children's Self-Regulation and Competence in School. Journal of Educational Psychology, 81, 143-154. http://dx.doi.org/10.1037/0022-0663.81.2.143

Gwet, K. L. (2008a). Computing Inter-Rater Reliability and Its Variance in the Presence of High Agreement. British Journal of Mathematical and Statistical Psychology, 61, 29-48. http://dx.doi.org/10.1348/000711006X126600

Hagger, M. S., Chatzisarantis, N. L. D., Culverhouse, T., \& Biddle, S. J. H. (2003). The Process by Which Perceived Autonomy Support in Physical Education Promotes Leisure-Time Physical Activity Intentions and Behavior: A TransContextual Model. Journal of Educational Psychology, 95, 784-795. http://dx.doi.org/10.1037/0022-0663.95.4.784

Hair Jr., J. F., Anderson, R. E., Tatham, R. L., \& Black, W. C. (1998). Multivariate Data Analysis (5th ed.). Upper Saddle River, NJ: Prentice Hall.

Lepper, M. R., \& Henderlong, J. (2000). Turning “Play” into “Work” and “Work” into "Play”: 25 Years of Research on Intrinsic versus Extrinsic Motivation. In C. Sansone, \& J. M. Harackiewicz (Eds.), Intrinsic and Extrinsic Motivation: The Search for Optimal Motivation and Performance (pp. 257-307). San Diego, CA: Academic Press.

http://dx.doi.org/10.1016/B978-012619070-0/50032-5

Lonsdale, C., Hodge, K., \& Rose, E. A. (2008). The Development of the Behavioral Regulation in Sport Questionnaire (BRSQ): Instrument Development and Initial Validity Evidence. Journal of Sport and Exercise Psychology, 30, 323-335.

Mageau, G., \& Vallerand, R. (2003). The Coach and Athlete Relationship: A Motivational Model. Journal of Sports Sciences, 21, 883-904. http://dx.doi.org/10.1080/0264041031000140374

Molanorouzi, K., Khoo, S., \& Morris, T. (2015). Motives for Adult Participation in Physical Activity: Type of Activity, Age, and Gender. BMC Public Health, 15, 66. http://dx.doi.org/10.1186/s12889-015-1429-7

Pelletier, L. G., Rocchi, M. A., Vallerand, R. J., Deci, E. L., \& Ryan, R. M. (2013). Validation of the Revised Sport Motivation Scale (SMS-II). Psychology of Sport and Exercise, 14, 329-341. http://dx.doi.org/10.1016/j.psychsport.2012.12.002

Pelletier, L., Fortier, M., Vallerand, R., \& Brière, N. (2001). Associations among Perceived Autonomy Support, Forms of Self-Regulation, and Persistence: A Prospective Study. Motivation and Emotion, 25, 279-306. http://dx.doi.org/10.1023/A:1014805132406

Pintrich, P. R., \& Maehr, M. L. (2002). Advances in Motivation and Achievement: New Directions in Measures and Methods. Oxford: Elsevier Science.

Reeve, J. (2002). Self-Determination Theory Applied to Educational Settings. In E. Deci, \& R. Ryan (Eds.), Handbook of Self-Determination Research (pp. 183-203). Rochester, NY: The University of Rochester Press. 
Rouse, P. C., Ntoumanis, N., \& Duda, J. L. (2013). Effects of Motivation and Depletion on the Ability to Resist the Temptation to Avoid Physical Activity. International Journal of Sport and Exercise Psychology, 11, 39-56. http://dx.doi.org/10.1080/1612197X.2012.717779

Ryan, R. M., \& Deci, E. L. (2007). Active Human Nature: Self-Determination Theory and the Promotion and Maintenance of Sport, Exercise, and Health. In M. S. Hagger, \& N. L. D. Chatzisarantis (Eds.), Intrinsic Motivation and Self-Determination in Exercise and Sport (pp. 1-19). Leeds: Human Kinetics Europe Ltd.

Standage, M., Duda, J. L., \& Ntoumanis, N. (2003). A Model of Contextual Motivation in Physical Education: Using Constructs from Self-Determination and Achievement Goal Theories to Predict Physical Activity Intentions. Journal of Educational Psychology, 95, 97-110. http://dx.doi.org/10.1037/0022-0663.95.1.97

Standage, M., Duda, J., \& Ntoumanis, N. (2006). Students’ Motivational Processes and Their Relationship to Teacher Rating in School Physical Education: A Self-Determination Theory Approach. Research Quarterly for Exercise and Sport, 77, 100-110. http://dx.doi.org/10.1080/02701367.2006.10599336

Trouilloud, D., \& Sarrazin, P. (2002). L'effet Pygmalion existe-t-il? Influence des attentes des enseignants sur la motivation et la réussite des élèves. Science et Motricité, 46, 69-94.

Vallerand, R. J. (1997). Toward a Hierarchical Model of Intrinsic and Extrinsic Motivation. In M. P. Zanna (Ed.), Advances in Experimental Social Psychology (Vol. 29, pp. 271-360). New York: Academic Press.

http://dx.doi.org/10.1016/s0065-2601(08)60019-2

Vallerand, R. J. (2007). Intrinsic and Extrinsic Motivation in Sport and Physical Activity: A Review and a Look at the Future. In G. Tennenbaum, \& R. Eklund (Eds.), Handbook of Sport Psychology (3rd ed., pp. 59-83). New York: John Wiley \& Sons. http://dx.doi.org/10.1002/9781118270011.ch3

Vallerand, R. J., \& Fortier, M. N. (1998). Measures of Intrinsic and Extrinsic Motivation in Sport and Physical Activity: A Review and Critique. In J. L. Duda (Ed.), Advances in Sport and Exercise Psychology Measurement (pp. 81-101). Morgantown, WV: Fitness Information Technology.

Vallerand, R. J., Blais, M., Brière, N., \& Pelletier, L. G. (1989). Construction et validation de l'échelle de motivation en éducation (EME) [Construction and Validation of the Educational Motivation Scale (EMS)]. Revue Canadienne des Sciences du Comportement, 21, 323-349. http://dx.doi.org/10.1037/h0079855

Wilson, P. M., \& Rodgers, W. M. (2004). The Relationship between Perceived Autonomy Support, Exercise Regulations and Behavioural Intentions in Women. Psychology of Sport \& Exercise, 5, 229-242.

http://dx.doi.org/10.1016/S1469-0292(03)00003-7

Wilson, P. M., Nehl, E., \& Baker, F. (2006). Predicting Physical Activity and Outcome Expectations in Cancer Survivors: An Application of Self-Determination Theory. Psycho-Oncology, 15, 567-578. http://dx.doi.org/10.1002/pon.990 